NBER WORKING PAPER SERIES

\title{
THE ROLE OF INFORMATION AND SOCIAL INTERACTIONS IN RETIREMENT PLAN DECISIONS: EVIDENCE FROM A RANDOMIZED EXPERIMENT
}

\author{
Esther Duflo \\ Emmanuel Saez \\ Working Paper 8885 \\ http://www.nber.org/papers/w8885 \\ NATIONAL BUREAU OF ECONOMIC RESEARCH \\ 1050 Massachusetts Avenue \\ Cambridge, MA 02138 \\ April 2002
}

We thank Daron Acemoglu, Orley Ashenfelter, Josh Angrist, David Autor, Abhijit Banerjee, David Card, Jonathan Gruber, Guido Imbens, Larry Katz, Jeffrey Kling, Botond Koszegi, Michael Kremer, Alan Krueger, David Laibson, Sendhil Mullainathan, and seminar participants at Berkeley, MIT, Princeton, and UCLA for very helpful comments and discussions. We gratefully acknowledge financial support from the National Science Foundation (SES-0078535). We are especially grateful to all the members of the Benefits Office of the University for their help and support in organizing the experiment. This paper does not reflect the views of the university or its benefits office. The views expressed herein are those of the authors and not necessarily those of the National Bureau of Economic Research.

(C) 2002 by Esther Duflo and Emmanuel Saez. All rights reserved. Short sections of text, not to exceed two paragraphs, may be quoted without explicit permission provided that full credit, including (C notice, is given to the source. 
The Role of Information and Social Interactions in Retirement Plan Decisions:

Evidence from a Randomized Experiment

Esther Duflo and Emmanuel Saez

NBER Working Paper No. 8885

April 2002

JEL No. D83, I22

\section{ABSTRACT}

This paper analyzes a randomized experiment to shed light on the role of information and social interactions in employees' decisions to enroll in a Tax Deferred Account (TDA) retirement plan within a large university. The experiment encouraged a random sample of employees in a subset of departments to attend a benefits information fair organized by the university, by promising a monetary reward for attendance. The experiment more than tripled the attendance rate of these treated individuals (relative to controls), and doubled that of untreated individuals within departments where some individuals were treated. TDA enrollment 5 and 11 months after the fair was significantly higher in departments where some individuals were treated than in departments where nobody was treated. However, the effect on TDA enrollment is almost as large for individuals in treated departments who did not receive the encouragement as for those who did. We provide three interpretations, differential treatment effects, social network effects, and motivational reward effects, to account for these results.

Esther Duflo

MIT

Department of Economics

Cambridge, MA 02142

and NBER

eduflo@mit.edu
Emmanuel Saez

Harvard University

Department of Economics

Cambridge, MA 02138

and NBER

saez@fas.harvard.edu 


\section{Introduction}

Low levels of savings in the United States have generated substantial interest in the question of what determines savings decisions. A vast literature has studied the impact of Tax Deferred Accounts (hereafter, TDA), such as Individual Retirement Accounts (IRAs) and $401(\mathrm{k}) \mathrm{s}$, on retirement savings decisions, ${ }^{1}$ and, concurrently, the impact of these plans' features on enrollment and contribution rates. In addition to the tax savings and economic incentives (such as employer's match), a number of recent studies emphasize the role of non-economic factors, such as social interactions, financial education, inertia, and commitment. Duflo and Saez (2000) study how individual participation in a TDA plan within a large university is affected by average participation in one's department. They obtain suggestive evidence that peer effects have a strong influence on the decision to enroll in TDA plans. Madrian and Shea (2001) and Choi et al. (2001a, 2001b) show that default rules have an enormous impact on employees' participation, contribution, and asset allocation. When employees are enrolled by default in a TDA, very few opt out and most employees do not change the default contribution rate or the default allocation of assets. Thaler and Bernatzi (2001) show that inducing employees to commit to contribute a large fraction of their pay raises to the TDA (the "Save More Tomorrow" program) has a dramatic positive impact on savings rates. Bernheim and Garett (1996) and Bayer, Bernheim, and Scholz (1996), Bernheim, Garett and Maki (1997), among others, study the role of financial education. They present evidence that financial education tends to be remedial ${ }^{2}$ but that it increases participation in savings plans, suggesting that employees may not be able to gather the necessary information on their own. This evidence, though suggestive, does not provide fully convincing proof that information and financial education can have a strong impact on TDA participation decisions, because employers'

\footnotetext{
${ }^{1}$ See Poterba, Venti and Wise (1996) and Engen, Gale and Scholz (1996) for a controversial debate summarizing the literature.

${ }^{2}$ Employers resort to it when they fail discrimination testing because the contribution rates of the not highly compensated employees are too low.
} 
decision to provide this information is endogenous. Recently, Madrian and Shea (2002) studied the effects of benefits seminars within a large firm and showed interesting evidence of self-selection in the decision to attend benefits: employees who attend seminars are much more likely to be recent enrollees in the TDA plan. They found modest positive effect of information seminars on TDA participation after a few months.

Financial education is generally recognized as an potentially important avenue to improve the quality of financial decision making. $71 \%$ of the fortune 500 companies systematically hold financial information sessions. A further $10 \%$ conducts them occasionally. ${ }^{3}$ The U.S. Treasury (Summers, 2000) outlined a proposal to improve financial literacy and increase the access to financial services of lower income American households. In particular, the report stressed the importance of information on savings instruments and the role of social interaction effects in the decision to save. The goal of this paper is to analyze the evidence from a random experiment to shed light on both the role of information and social interactions on the employees' decision to enroll in the employer sponsored TDA plan of a large university. Our analysis improves upon the studies discussed above because the source of identification comes directly from the randomized experiment. This allows us to overcome some of the very difficult identification problems in the presence of peer effects, described notably in Manski $(1993,1995) .{ }^{4}$

Each year, the university organizes and invites all its employees to a benefits fair in order to provide information on benefits. In particular, a stated goal of the fair is to increase the enrollment rate in TDA, which the university administration feels is too

\footnotetext{
${ }^{3}$ This data come from a telephone survey of all 500 companies we conducted in the summer 2001.

${ }^{4}$ In spite of these difficulties, there is a growing empirical literature on peer effects using observational analysis which essentially focuses on social behavior, and the adoption of new technologies. For example, Case and Katz (1991) and Evans, Oates and Schwab (1992) on teenagers' behavior, Bertrand, Mullainathan and Luttner (1998) on welfare participation, Munshi (2000a) on contraception, and Besley and Case (1994), Foster and Rosenzweig (1995) and Munshi (2000b) on technology adoption in developing countries. Sorensen (2001) analyzes peer effects within departments of a university in the choice of Employer sponsored Health Plans using a methodology related to Duflo and Saez (2000).
} 
low (around 35\%). Obviously, comparing the TDA enrollment decisions of fair attendees to those who did not attend the fair would not provide convincing evidence of a causal effect of fair attendance on TDA enrollment, because the decision to attend the fair is endogenous. ${ }^{5}$ To circumvent this selection problem, we have implemented the following experiment. We selected a random sample of employees not yet enrolled in the TDA and sent them an invitation letter promising a $\$ 20$ reward for attending the fair. This type of experiment is a classical encouragement design, often used in medical science, where treatments are offered to a random group of patients who then decide whether or not to take the treatment. ${ }^{6}$ Encouragement designs are rare in economics. An example is the study by Powers and Swinton (1984) who analyze the effect of hours of study on test scores by randomly mailing test preparation materials to students to encourage them to study.

The second objective of our study is to analyze peer effects within departments. We therefore designed our experiment such that we are able to estimate social interaction effects. Namely, "treated" individuals who were sent the invitation letter were selected only from a random subset of departments (the "treated" departments). A number of recent studies have also used experimental or quasi-experimental situations to study social interaction effects. Kremer and Miguel (2001) is perhaps the most closely related to our study. They analyze an experiment design to evaluate own and external effects of a medical treatment against intestinal worms for children in schools in Kenya, and obtain evidence of spillover effects. They show that children in treated schools who did not get the medicine were positively affected. However, in their case, variation in treatment

\footnotetext{
${ }^{5}$ For example, individuals who had already decided to enroll, but are not sure exactly how much they wanted to contribute, may be more likely to attend the fair (see Madrian and Shea (2002) for evidence of selection in the decision to attend information sessions.

${ }^{6}$ For example, Permutt and Hebel (1989) study the effect of maternal smoking on birth weight using randomly assigned free smoker's counseling to encourage mothers to quit smoking. Imbens et al. (2000) analyze of the effect of flu shots (recommended but not required) to a random subset of patients on flu outcomes.
} 
status within a school was not randomized but occurred because some children were not present on treatment day. Katz et al. (2001) use random assignment to a housing voucher program for households living in high poverty public housing projects in the Boston area and find improvement of treated families in safety, health, and exposure to crime. $^{7}$ Sacerdote (2001) uses random assignment of first-year students in Dartmouth college dorms and finds peer effects strongly influence levels of academic effort as well as decisions to join social groups. These latter two studies on social interactions differ from ours mainly because they study the effect of assigning individuals to different peer groups, whereas in our study, peer groups (departments) are fixed, and we analyze how individual decisions are affected by an exogenous change on the information set of some members of the peer group.

The first stage of our study analyzes the effect of the invitation letter on fair attendance. Treated individuals are three times as likely to attend the fair as control individuals. Interestingly, control individuals in treated departments are twice as likely to attend the fair as control individuals in non-treated departments, despite the fact that only original letter recipient could claim the $\$ 20$ reward. This shows that the invitation letters not only increased the fair attendance rate for individuals who received them but had also a spill-over social effect on their colleagues within departments. The direct effect of the letter on attendance (purged from the peer effects) can also be estimated by comparing the attendance rates of treated and control individuals within treated departments only.

The second stage of the study tries to estimate the causal effect of fair attendance and social effects on the decision to enroll in the TDA. We show that, 5 and 11 months after the fair, individuals in treated departments are significantly more likely to have started contributing to the TDA than control individuals. This shows that our experiment, and hence the fair, was successful in increasing TDA enrollment. However, there is no significant difference in TDA enrollment between those who actually received our

\footnotetext{
${ }^{7}$ Following our previous discussion, the voucher program can be seen as an encouragement design to leave public housing projects.
} 
encouragement letter and those in the same departments who did not. We propose three different interpretations, not necessarily mutually exclusive, to account for these facts. First, this might be evidence of differential treatment effects of fair attendance on TDA enrollment. Employees who come to the fair only because of the financial reward are different from those who decide to come to the fair because of their colleagues, and it is plausible to think that the treatment effect is larger for the latter group than for the former. Second, there might be social network effects within departments. Fair attendees might be able to spread information obtained from the fair in their departments. Third, our results might also be explained by motivational reward effects. Paying individuals to attend the fair might affect their subjective motivation and therefore the perceived value or quality of the information they obtain at the fair. Such effects have been documented in the social psychology literature. Our experiment does not allow us to separately identify these three effects but it allows us to conclude that the important decision about how much to save for retirement can be affected by small shocks such as a very small financial reward and/or the influence of peers, and thus does not seem to be the consequence of an elaborate decision process.

The remainder of the paper is organized as follows. Section 2 describes the benefits fair and the design of our experiment. Section 3 discusses the reduced form evidence. Section 4 develops a simple model to guide the subsequent analysis of our results. Section 5 provides additional evidence from a follow-up questionnaire and a general interpretation of our results. Finally, Section 6 offers a brief conclusion. 


\section{Context and Experiment Design}

\subsection{Benefits and Benefits Fair}

The university we study has approximately 12,500 employees. About a quarter of the employees are faculty members. Our study was limited to non-faculty employees only. ${ }^{8}$ The university provides retirement benefits to its employees through a traditional pension plan and a complementary Tax Deferred Account (TDA) plan. Part of the traditional pension plan is a Defined Contribution (DC) plan whereby $3.5 \%$ of an employee's salary is put into an individual mutual fund account. ${ }^{9}$ Employees can also voluntary contribute to a TDA 403(b) plan. ${ }^{10}$ Every employee can contribute to the 403(b) plan any percentage of their salary up to the IRS limit $(\$ 10,500$ per year for each individual in 2001). The university does not match contributions. In both the DC and the TDA plans, employees can choose to invest their contributions in any number of four different vendors.

Each year, the university organizes a benefits fair where all employees are invited to come and learn about all benefits (such as health benefits, retirement benefits, etc...) provided by the university. The fair is held on two consecutive days in early November in two different locations, each one close to the two separate main university campuses. About one week before the fair, every employee receives a letter through university mail inviting her to attend the fair. This letter also provides a brief description of the event. At the same time, under separate cover, every employee receives a packet describing in detail university benefits along with enrollment forms. November is "open enrollment" month during which each employee may change her benefits choices by submitting the enrollment form. If the employee does not send back the form, her benefits choices are automatically carried over from the previous year. However, employees are free to enroll in the TDA or

\footnotetext{
${ }^{8}$ Duflo and Saez (2000) present suggestive evidence that staff employees TDA choices are not influenced by faculty choices and vice-versa.

${ }^{9}$ Non-faculty employees have an additional Defined Benefits plan in addition to the DC plan.

${ }^{10} 403(\mathrm{~b})$ plans are very similar to the better known $401(\mathrm{k})$ plans but their use is restricted to not-forprofits firms.
} 
change their contribution level or investment decision at any time throughout the year.

In both locations, the fair is held in a large hotel reception room. There are a large number of stands representing the university Benefits Office, and the various health and retirement benefits service providers. The university Benefits Office offers information on all benefits through direct conversation with benefits office staff present at the fair, and through a number of information pamphlets freely available at their stand. The benefits office also provides information on how the other stands at the fair are organized. These other stands are run by each of the specialized service providers. For example, each of the mutual fund vendors has a stand at which they provide information about the TDA plan and the specific services they offer within that plan. The fair also offers individuals the chance to use a specially designed computer program to analyze their specific situation. Employees are free to come anytime during the three and a half hours during which the fair is held, and visit any number of stands they want.

\subsection{Experiment Design}

The university organizes the annual fair in order to disseminate information about benefits and help its employees make better decisions. The university feels the participation rate among staff (34\%) is too low compared to other universities, and that this may be due to lack of information.

A simple comparison between the benefits choices of those who attend the fair and those who do not does not provide an unbiased estimate of the effect of the fair. Clearly, those who plan to change their benefits choices may be more likely to attend the fair. Therefore, in order to to identify the causal effect of fair attendance on TDA enrollment, we set up an "encouragement design", by promising a random subset of employees a small amount of money for attending the fair. In previous work (Duflo and Saez, 2000), we have shown that the decisions to participate into the TDA are very correlated among individuals within departments, which suggests the existence of social effects in enrollment decisions. Therefore, in order to shed light on social effects within departments, not all 
individuals within the treated departments received a letter. We can thus measure peer effects using individuals who didn't receive a letter, but who had peers that did.

We used a cross-section of administrative data provided by the university on all its employees as of August 2000. We restricted the sample to staff employees (i.e. nonfaculty employees) aged less than 65 and eligible to participate in the TDA. ${ }^{11}$ Of the 9,700 employees meeting these criteria, around 3,500 were enrolled in the TDA as of August 2000. From now on, we refer to these individuals as the pre-enrolled individuals. The remaining 6,200 individuals were not enrolled in the TDA by August 2000. As very few employees stop contributing to the TDA once they are enrolled, ${ }^{12}$ we focus on the decision to start participating into the TDA. Thus the sample of 6,200 non-enrolled individuals is our sample of primary interest.

In the first step, we randomly selected two thirds of the departments of the university (220 out of a total of 330) as follows. In order to maximize the power of the experiment (in a context in which we know there are strong department effects), we first matched departments according to their size (i.e. number of employees) and participation rate in the TDA before the fair. We separated department into deciles of participation rates among the staff. Each decile contains 33 departments. We then ranked them by size within each decile, and formed groups of three departments by putting three consecutive departments on these lists in the same triplet. Within each of these triplets, we randomly selected two departments to be part of the group of treated departments. From now on, we refer to the treated departments as the $T$ departments and to the control departments as the 0 departments.

In the second step, within each of the treated departments, any individual not enrolled as of August 2000 was selected with probability one half. This treatment group is com-

\footnotetext{
${ }^{11}$ Part time employees working less than 20 hours per week are not eligible for the TDA. Most of these employees are students of the university.

${ }^{12}$ Only 80 of the 3,500 employees enrolled in the TDA stopped contributing during the one year period we examine. More than five times as many employees started contributing to the TDA during the same period.
} 
posed of 2,039 individuals. We referred to this group as the Treated individuals and denote them by $T 1$ ( $T$ for Treated department and 1 for being selected). The group formed by the employees in the treated departments who were not selected contains 2,129 individuals and is denoted by $T 0$ ( $T$ for Treated department and 0 for not being selected). In total, there are 4,168 individuals in the treated departments. The control group is formed by employees in the control departments where no treatments were selected; it contains 2,043 individuals and is denoted by 0 .

One week before the fair, we sent a letter via university mail to the 2,039 employees in the treatment group $T 1$. The letter reminded them of the fair and informed them that they would receive a check for $\$ 20$ from us if they were to come to the fair and register at our desk. This letter is reproduced in facsimile in the appendix.

At the fair, we set up a stand for the employees who received our invitation letter to register their name. Unfortunately, the benefits office did not authorize us to record the names of the fair participants who did not receive our letter. However, we recorded their total number: a student stood at the fair entrance and distributed a coupon to each person who entered the hall. The coupons had different colors according to the status of the participant (active or retired), which allowed us to count the number of active employees who attended the fair. Everybody had to pass through the narrow entrance enter the fair, and the few people who refused the coupon were carefully counted. We are thus confident that we accurately recorded the number of participants. In order to collect information on the TDA status and the department affiliation of all the fair participants, we organized a raffle. The coupons that were distributed at the entrance of the fair had two parts, with a number written twice. Each fair attendant who wanted to participate in the raffle gave us half of the coupon. We asked all the raffle participants their department affiliation and whether they were currently enrolled in the TDA. The raffle was held every 30 minutes, and the prize was a $\$ 50$ Macy's gift certificate. A total of 1,617 active employees attended the fair. 573 of them had received our letter. Out of the remaining 1,044 employees, 766 (i.e., about three quarters) came to play the raffle and registered 
their department affiliation and TDA enrollment status. An important issue that arises is whether there was selection by $T$ versus 0 departments in who decided to play the raffle (and hence provide their department affiliation and TDA status). We do not believe this was the case: most of those who refused to play the raffle did so because they visited our stand just after the previous raffle had been played, and did not want to stay at the fair long enough to wait for the next raffle. Therefore, we assume that fair attendants who did not register their department affiliation are distributed between $T$ and 0 departments as those who did register. Therefore, in what follows, we scale up the attendance recorded in each department by a factor of $1,044 / 766 .^{13}$

In order to assess the effects of the experiment and the fair on TDA participation, the university provided us three waves of data. The first wave was obtained in September 2000, just before the fair. The second wave was from March 2001 (4.5 months after the fair) and the third wave from October 2001 (11 months after the fair).

Finally, we sent a short questionnaire (reproduced in the appendix) to 917 employees in April 2001. The questionnaire was designed to assess the intentions and evaluate the knowledge of employees about retirement benefits. An additional goal of sending out the questionnaire was to remind those that were not yet enrolled of their TDA status, and (potentially) provide them a cue to think about enrolling in the TDA. In the questionnaire, we asked employees whether they were enrolled in the TDA, why they were not enrolled, whether they saved for retirement through other means, and whether they had attended the fair. In order to induce employees to send back the questionnaire, we promised a $\$ 10$ Macy's gift certificate to any employee who would send back the questionnaire within 6 weeks. We selected 917 employees to receive the questionnaire as follows. First, we restricted the sample to those who were not enrolled in the TDA by March 2001. Second, one third of employees (301) were selected among the 573 fair participants who did receive the invitation letter. The second third (311) of employees were selected among the 1,499

\footnotetext{
${ }^{13}$ We present in Section 5 evidence supporting our non-selection hypothesis. However, we will discuss how modifying this assumption would affect our result.
} 
employees who received the invitation letter but did not come to the fair. The last third (305) were selected among our control group (those who did not receive the invitation letter). ${ }^{14}$ We did not intentionally leave out any departments, but since the number of questionnaires was not very large, there are a number of departments where we did not send any questionnaire. ${ }^{15}$

\section{Results: Summary statistics and Reduced form dif- ferences}

In the presence of social interactions, employees who work in departments where some people received the letter can be affected by the experiment even if they did not receive the letter themselves. They may be more likely to come to the fair themselves, because they are reminded by others of the event, or because employees come to the fair in groups. ${ }^{16}$ They may also be more likely to enroll in the TDA even if they do not come to the fair themselves, either because they are directly influenced by the action of those who went to the fair, or because these individuals share the information they gathered at the fair. Thus, employees are potentially subjected to two kinds of treatments: they can receive the invitation letter themselves (group $T 1$ ), and they can be in a group where some employees received the letter (departments $T$ ). Those who receive the letter are, obviously, subject to both treatments.

The summary statistics are displayed in Table 1, broken down into 4 groups. In columns (1) to (3), we present the statistics for individuals who belong to treated departments $T$. Column (1) has the statistics for the entire group (group T), column (2) has the statistics for the group of treated individuals (group T1), and column (3) has the statistics for the untreated individuals in treated departments (group T0). In column (4),

\footnotetext{
${ }^{14}$ Out of these 305 individuals, 160 are from the $T 0$ control group and 145 are from the 0 control group.

${ }^{15}$ These departments tend to be smaller, but once we control for the dummy indicating in which group the department belongs, the difference in size is small.

${ }^{16}$ This is something we observed at the fair.
} 
we present the statistics for individuals who belong to the untreated departments (group 0 ). It is important to note that all these statistics (except the first row of Panel A and the second row of Panel B) focus only on individuals not enrolled in the TDA on September 2000 before the fair. In Table 2, we present differences in the same variables across groups. The differences are estimated by a regression, which includes a triplet fixed-effect, and corrects standard errors for clustering at the department level. ${ }^{17}$ Columns (1), (2), (3), and (4) present the differences between group $T$ and group 0 , group $T 1$ and group $T 0$, group $T 0$ and group 0 , group $T 1$ and group 0 respectively.

Panel A presents background characteristics. In the first wave (on September 2000 before the fair), a very small proportion of employees started contributing to the TDA (the first wave is from September 2000, but we used data from August 2000 to construct the randomization), but there is no apparent difference across groups in these proportions. Since we are interested in changes caused by the fair, we focus in the remaining of the analysis on individuals who were still not enrolled in the first wave (i.e. by September 2000). Since the groups were chosen randomly, the mean of observable characteristics such as sex, years of service, annual salary, and age, are very similar across groups. As expected, none of the differences are significant.

In panel $\mathrm{B}$, we can see that our inducement strategy had a strong effect on the probability of attending the fair: in treated departments, as much as $21.4 \%$ of individuals attended the fair. In control departments, fewer than $5 \%$ of individuals attended the fair. The difference, $16.5 \%$, is highly significant (Table 2, column (1)). Comparing treated individuals versus controls in the treated departments in columns (2) and (3) of Table 1 shows that social effects account for a large part of the effect of our experiment on fair attendance. The fair attendance rate of those who received our letter is $28 \%$, and is $15.1 \%$ for those in the treated departments who did not receive the letter. Thus, the direct effect

\footnotetext{
${ }^{17}$ As it is visible from inspecting Table 1 , this does not affect the point estimates of the differences. However, it reduces the standard errors, by absorbing some unexplained differences across departments of similar sizes and pre-fair TDA enrollment rates.
} 
of receiving the letter (taking out any social effect, which are the same for groups $T 0$ and T1) displayed on column (2) of Table 2 is $13.8 \%$. The difference in the attendance rate between the $T 0$ group and the 0 group (which is solely due to social effects) is almost as high, at $10.2 \%$, and highly significant (see column (3) of Table 2). ${ }^{18}$

In Panel C, we look at TDA participation. After 4.5 months, relatively few people have enrolled. However, employees in treated departments are already significantly more likely to be enrolled than employees in control departments (4.9\% versus $4 \%)$. This represents a $24 \%$ increase in the enrollment rate. There is no significant difference between groups $T 1$ and $T 0$, however. ${ }^{19}$ The difference between groups $T 0$ and 0 is 1.26 percentage points and significant. Eleven months after the fair, enrollment is higher still, and the difference between treated departments and control departments is 1.4 percentage point and significant as well (it represents a 19\% increase in TDA enrollment). The difference between groups $T 1$ and $T 0$ is now positive, but still very small and insignificant. The difference between group $T 0$ and group 0 is positive, and significant at the $10 \%$ level. Obtaining significant differences between these randomly chosen groups means that our experiment did have an impact on TDA enrollment. This impact is large in relative terms (an increase of $20 \%$ in the likelihood of enrollment after 11 months). However, because people update their TDA status very infrequently, it is small in absolute terms (an increase of only 1.5\% points of enrollment, on a base of 36\%)). This effect is tiny compared to interventions that change the default rules for TDA enrollment (such as in Marian and Shea (2001), and Choi et al. (2001a, 2001b)) or that offer individuals the option to allocate automatically future pay rises to TDA contributions (Thaler and Bernatzi (2001)).

\footnotetext{
${ }^{18}$ This result is of course sensitive to the assumption we made about department affiliation of fair attendants who did not register at our desk. If we make the extreme assumption that all non registered individuals come from 0 departments, the fair participation rate for $T 0$ group would fall down to $11 \%$ but still be higher than for group 0 (which would go up to $9 \%$ ). In addition, we show below that the increase in fair attendance in the $T 0$ group is parallelled by an increased in their TDA participation.

${ }^{19}$ The point estimate in table 2 is even slightly negative, with a t-statistic of about 1.
} 
In summary, the results we present in Tables 1 and 2 suggest that the incentive scheme had a large effect on fair participation of treated departments (due to a combination of the direct encouragement effect and the multiplier effect of social interactions), as well as a significant effect on TDA enrollment. This shows that the fair had an effect on the decision to enroll in the TDA. However, within treated departments, there is no difference in TDA enrollment between those who received the letter and those who did not. The next section presents simple models to interpret these results.

\section{Understanding the Effects of the Experiment}

\subsection{Fair attendance}

Let us first analyze the decision to attend the fair. As we have seen, receiving our invitation letter with its promise of a $\$ 20$ reward increases the probability of attending the fair. Denote this increase in the probability of attending the fair by $\delta$. As we have seen, there are peer effects in the decision to attend the fair because $T 0$ individuals are more likely to attend than 0 individuals. A simple way to capture these two effects is to posit the simple following reduced form specification:

$$
f^{i}=\delta L^{i}+\mu D^{i}+\epsilon^{i}
$$

where $f^{i}$ is the dummy for attending the fair for individual $i, \epsilon^{i}$ is a random individual effect, $L^{i}$ is a dummy indicator for receiving the inducement letter, and $D^{i}$ a dummy indicator for being in a treated department. ${ }^{20}$ Column (1) of Table 3 presents the estimation parameters $\delta$ and $\mu$ in (1). Actually, these two parameters were already estimated in the reduced form results presented in Table 2. Taking the difference of the averages of

\footnotetext{
${ }^{20} \mathrm{As} f^{i}$ is a $0-1$ variable, equation (1) is not strictly correct. The left-hand-side should be replaced with the probability of attending the fair for individual $i$, and restrictions imposed on the parameters and the distribution of $\epsilon^{i}$ to ensure that this number is always between 0 and 1 . These technicalities can be taken care of easily and thus are ignored to keep the presentation focused on identification questions.
} 
equation (1) across groups $T 1$ and $T 0$ shows that $\delta=\bar{f}_{T 1}-\bar{f}_{T 0}$ where $\bar{f}_{T i}$ denotes average fair attendance among individuals in group $T i, i=0,1$. Similarly, taking the difference of the averages of equation (1) across groups $T 0$ and 0 shows that $\mu=\bar{f}_{T 0}-\bar{f}_{0}$.

Peer effects in the decision to attend the fair can take two forms. First, if an individual in a given department decides to go to the fair, she might talk to her colleagues about the fair, give them information about the details, or ask them to join her, and thus increase the probability her colleagues attend the fair. Second, it is also conceivable that an employee receiving the letter might talk about it to her colleagues, even if she does not go herself to the fair, and thus also affect their attendance rate. For example, colleagues of those who received the letter may think that if the benefits office is ready to pay some people $\$ 20$ to attend the fair, it must be sufficiently important for them to attend as well. We model these peer effects by assuming that the average fair attendance rate and the average "letter rate" (defined as the number of employees who received the letter divided by the number of employees in the department) in each department influence the individual fair attendance decision.

Let us denote by $\bar{f}$ the average attendance rate in the department of individual $i$, and by $\bar{L}$ the letter rate in the department of individual $i$. The invitation letter effect and the peer effects on fair participation can be captured by the simple following linear model (see e.g. Manski (1993))

$$
f^{i}=\delta L^{i}+\Lambda \bar{L}+\beta_{1} \bar{f}+v^{i}
$$

where $v^{i}$ is the random individual effect, and $\beta_{1}<1$, and $\Lambda$ are the peer effect coefficients. This equation states that getting the letter increases the own probability of attending the fair by $\delta$, and the probability of everybody in the department of attending by $\Lambda / N(N$ being the number of employees in the department), and that an exogenous direct increase in fair attendance of 1 percent translates into a final increased fair attendance of $1 /\left(1-\beta_{1}\right)$ percent through the multiplier peer effect.

Obviously, our experiment does not allow us to identify all three parameters $\delta, \Lambda$, 
and $\beta_{1}$ because we have only two instruments: receiving the letter $L^{i}$ and the dummy indicator $D^{i}$ for being in a $T$ (versus 0) department. However, the following semi-reduced form of equation 2 is identified,

$$
f^{i}=\delta L^{i}+\delta^{R} \bar{L}+v^{\prime i}
$$

Equation (3) can be easily derived from (2) by first averaging equation (2) by department to obtain an expression for $\bar{f}$, and then plugging this expression for $\bar{f}$ in (2). Simple algebra shows that $\delta^{R}=-\delta+(\Lambda+\delta) /\left(1-\beta_{1}\right)$. The parameters $\delta$ and $\delta^{R}$ of equation (3) are identified with our experiment ${ }^{21}$ and can be estimated with an IV regression using $L^{i}$ and $D^{i}$ as instruments. ${ }^{22}$ Column (2) of Table 3 presents the estimate of equation (3). The coefficient of the average number of letters is 0.28 , and is significant: an increase in $10 \%$ in the proportion of people who received a letter in the department lead to an increase of $2.8 \%$ in participation of those who did not themselves receive the letter.

It is perhaps reasonable to impose the additional restriction on equation (2) that $\Lambda=0$, i.e., a person receiving a letter can influence her colleagues fair attendance only if she decides to go to the fair. In that case, equation (2) is identified and $\beta_{1}$ can be estimated by running the IV regression (2) on the sample of individuals not enrolled in the TDA by September 2000, using $L^{i}$ and $D^{i}$ as instruments. The results are reported on column (3) of Table 3. The estimate we obtain for $\beta_{1}$ is large and precisely estimated: a $10 \%$ increase in attendance increases the probability that an individual attends the fair by 7.5\%. Put another way, the multiplier peer effect is $1 /\left(1-\beta_{1}\right)=4$, that is, an additional person induced to go to the fair because of the letter will induce, through a trickle-down effect, on average four additional individuals to attend the fair.

\footnotetext{
${ }^{21}$ This specification is similar to that of Acemoglu and Angrist (1999), who seek to estimate human capital externalities on earnings.

${ }^{22}$ The average $\bar{L}$ is not exogenous because it is computed over all employees (enrolled or not in the TDA by September 2000).
} 


\subsection{TDA Participation}

\subsubsection{The Model}

We showed in Section 3 that individuals in group $T 1$ are more likely to attend the fair than individuals in group $T 0$ but only equally likely to enroll in the TDA after the fair. Individuals in groups $T 1$ and $T 0$ are in the same departments and thus exposed to the same network effects at the department level. The only difference between the $T 1$ and $T 0$ groups is that $T 1$ individual received the inducement letter and hence are more likely to have attended the fair. This suggests that the direct fair effect is zero for those who attend the fair just because of the $\$ 20$ reward. Reduced form evidence from Section 3 also showed that individuals in group $T 0$ are more likely than individuals in group 0 both to attend the fair and to enroll in the TDA afterward. Three phenomena can explain these results.

First, as individuals in group T0 are more likely to attend the fair than group 0 individuals, it is plausible to think that for this group, attending the fair has had a positive effect on their TDA participation. It is important to note that this positive treatment effect for group T0 individuals (compared to group 0 individuals) is not necessarily contradictory with the zero treatment effect for group $T 1$ individuals (compared to group $T 0$ individuals) because these treatment effects are not measured for the same population. The latter effect is the treatment effect of the fair for those individuals who come because of the inducement letter while the former effect is the treatment effect of the fair for those individuals who are induced to come to the fair because they have been influenced to attend by their colleagues. It is plausible to think that individuals who attend the fair just for the $\$ 20$ might not be very interested in the content of the fair and thus do not get much out of it. In contrast, individuals induced to come by their colleagues (with no financial reward) are likely to be more interested by the event and thus end up being more influenced by what they learn at the fair. We will develop and formalize this differential treatment effect below using the theory of Local Average Treatment Effects (LATE) 
developed by Imbens and Angrist (1994), and Angrist, Imbens, and Rubin (1996).

The second reason why group T0 individuals are more likely to enroll in the TDA than group 0 individuals is that, because of our experiment, $T$ departments are different from 0 departments and individuals may be influenced by social network effects. Peer effects within departments could influence TDA enrollment through two channels. First, individuals who attend the fair might share the information obtained on the TDA with their colleagues and thus increase the enrollment rate in their department. ${ }^{23}$ Second, an individual who decides to enroll in the TDA might also discuss her decision with colleagues, and induce some of them to enroll as well.

Third and more subtle, it is conceivable that, even for an individual who would have come to the fair with no external inducement, receiving the letter offering the $\$ 20$ reward modifies her psychological motivation for attending the fair. Because the individual is now paid to attend the fair, she might convince herself that she is coming just for the $\$ 20$ and thus that she is not really interested in the content of the fair. This type of effect is not standard in economic models but there is substantial evidence in the psychology literature on the motivational consequences of rewards. This literature is summarized in Ross and Nisbett (1991) (pp. 65-67). Festinger and al. (1959) and Cooper et al. (1978) showed that providing people with small financial incentives for acting as if they hold a given belief promotes greater change in the "rewarded" direction than providing them with large incentives. Perhaps most closely related to our setting, Lepper et al. (1973) showed that school children who are rewarded to play with magic markers are less likely to enjoy it than children who are not, as if "play" had subjectively turned into "work". These results generated a substantial amount of interest because they go against the conventional reinforcement theory that would appear more intuitive.

These three effects, namely the differential treatment effect, the social network effect,

\footnotetext{
${ }^{23}$ We assume, however, that only fair attendees who are not enrolled in the TDA, can induce their colleagues to start enrolling in the TDA. Individuals already enrolled in the TDA presumably influence their colleagues directly through the second channel and not through the information collected at the fair.
} 
and the motivational reward effect can be captured the following simple linear model as follows. ${ }^{24}$ Let us assume that fair attendance increases the probability of TDA participation of individual $i$ by $\gamma^{i}$. Let us denote by $y^{i}$ the dummy for individual participation in the TDA. We posit the following specification

$$
y^{i}=\gamma^{i} f^{i}+\Gamma \bar{f}+u^{i}
$$

The fact that $\gamma^{i}$ can vary from individual to individual captures the potentially differential treatment effect. The social network effect is captured by the average fair participation rate $\bar{f}$ in the department. Finally, the motivational reward effect can be captured by assuming that the treatment effect $\gamma^{i}$ is potentially (negatively) correlated with the letter treatment $L^{i}$. In order to simplify the presentation, let us assume that $\gamma^{i}$ takes to following simple form

$$
\gamma^{i}=\gamma_{S}^{i}-\nu L^{i}
$$

where $\gamma_{S}^{i}$ is independent of $L^{i}$ (this is the standard treatment effect component), and $\nu$ represents the motivational reward effect. Assuming no motivational reward effect amounts to simply assuming that $\nu=0$ and thus that $\gamma^{i}$ is independent of $L^{i}$.

Each individual belongs to one of the groups $T 1, T 0$, or 0 . In order to define treatment effects of fair attendance on TDA enrollment, it is useful to introduce the notion of potential outcomes for fair attendance. For each individual, we denote by $f^{i}(T 1), f^{i}(T 0)$, and $f^{i}(0)$ the fair attendance decision of individual $i$, had he been in group $T 1, T 0$, or 0 . Obviously, for each individual $i$, we observe only one of the three potential outcomes for fair attendance. As the literature on differential treatment effects has recognized (see Imbens and Angrist (1994)), in order to be able to identify parameters of interest, we need to make the following assumption:

\footnotetext{
${ }^{24}$ It would be possible to develop a more general non-linear model but this would not change our estimation strategy and interpretation. Therefore, we consider only the simple linear framework.
} 
Assumption 1 Monotonicity Assumption: for each individual $i, f^{i}(T 1) \geq f^{i}(T 0) \geq$ $f^{i}(0)$.

This assumption states that receiving the letter can only encourage individuals to attend the fair (and in no case deter them), and that having one's colleagues receive the letter can also only encourage an individual to attend the fair (relative to the situation where no colleagues receive the letter). This assumption sounds very plausible in the situation we analyze. The Monotonicity assumption implies that the population can be partitioned into four different types.

First, the never takers are individuals such that $f^{i}(T 1)=f^{i}(T 0)=f^{i}(0)=0$. These individuals do not attend the fair and would not attend regardless of the group to which they belong. Second, we define the financial reward compliers type as individuals such that $f^{i}(T 1)=1>f^{i}(T 0)=f^{i}(0)=0$. These individuals attend the fair only if they receive the letter with the financial reward promise. Third, we define the social interaction compliers as individuals such that $f^{i}(T 1)=f^{i}(T 0)=1>f^{i}(0)=0$. These individuals would not attend the fair if nobody in their department receives the letter, but attend the fair if they are in a treated department (whether or not they themselves receive the letter). Finally, we define the always takers as individuals such that $f^{i}(T 1)=f^{i}(T 0)=f^{i}(0)=1$. These individuals attend the fair regardless of the group to which they belong.

We make the following additional assumption.

\section{Assumption 2 Exclusion restriction assumption: $u^{i}$ is independent of $L^{i}$}

The assumption that the error term $u^{i}$ is independent of the letter assignment status $L^{i}$ means that the letter inviting the employee to the fair has no direct effect on TDA participation decisions of those who do not attend the fair (beyond its effect on individual and departmental fair attendance). ${ }^{25}$ The letter we sent did not mention TDA but only

\footnotetext{
${ }^{25}$ However note that assumption 1 does not rule out the possibility that the letter can affect the TDA status of those who attended the fair, by reducing the fair's effectiveness (through the motivational reward effect described above).
} 
benefits in general, and did not contain any mention of the employee's TDA status (see the facsimile in appendix).

To assess the extent to which written communication could affect decisions, we send the questionnaires described in section 2 , which asked detailed questions about TDA status (see appendix). There is no significant difference in TDA participation after 6 months between departments to which we sent the questionnaire and departments to which we did not (the difference is actually negative at -0.093 percentage points with a standard error of 1.3 percentage points). Within departments to which the questionnaire was sent, the difference is only 0.90 percentage points (with a standard error of 0.94 percentage points) and not statistically significant either. Therefore, the targeted questionnaire on TDA did not seem to affect individuals' participation to the TDA. It is thus is plausible to think that, as stated in Assumption 1, a fair invitation letter does not directly affect TDA enrollment. This echoes the results in Choi et al (2001a), who sent two versions of a questionnaire to randomly selected employees, and found that employees who received a questionnaire with more questions about retirement savings were no more likely to subsequently enroll in the TDA than those who received a version without those questions. ${ }^{26}$

Taking the average of equation (4) over groups $T 1$ and $T 0$, and taking the difference, we obtain

$$
\bar{y}_{T 1}-\bar{y}_{T 0}=E\left[y^{i} \mid T 1\right]-E\left[y^{i} \mid T 0\right]=E\left[\gamma_{S}^{i} f^{i}-\nu f^{i}+\Gamma \bar{f}+u^{i} \mid T 1\right]-E\left[\gamma_{S}^{i} f^{i}+\Gamma \bar{f}+u^{i} \mid T 0\right] .
$$

Using the exclusion assumption stating that $u^{i}$ is independent of $L^{i}$, we have

$$
\bar{y}_{T 1}-\bar{y}_{T 0}=E\left[\gamma_{S}^{i}\left(f^{i}(T 1)-f^{i}(T 0)\right)\right]-\nu E\left[f^{i} \mid T 1\right] .
$$

Using the monotonicity assumption, we then obtain

$$
\bar{y}_{T 1}-\bar{y}_{T 0}=E\left[\gamma_{S}^{i} \mid f^{i}(T 1)-f^{i}(T 0)=1\right] \cdot P\left(f^{i}(T 1)-f^{i}(T 0)=1\right)-\nu P\left(f^{i}(T 1)=1\right)
$$

As $P\left(f^{i}(T 1)=1\right)=\bar{f}_{T 1}$ and $P\left(f^{i}(T 1)-f^{i}(T 0)=1\right)=\bar{f}_{T 1}-\bar{f}_{T 0}$, we finally obtain

\footnotetext{
${ }^{26}$ This is also evidence that information conveyed through mailing may not have a great impact on final decisions.
} 


$$
\frac{\bar{y}_{T 1}-\bar{y}_{T 0}}{\bar{f}_{T 1}-\bar{f}_{T 0}}=E\left[\gamma_{S}^{i} \mid f^{i}(T 1)-f^{i}(T 0)=1\right]-\nu \cdot \frac{\bar{f}_{T 1}}{\bar{f}_{T 1}-\bar{f}_{T 0}} .
$$

Thus comparing individuals $T 1$ and individuals $T 0$ provides an estimate of the sum of the direct average treatment effect for financial reward compliers and the motivational reward effect. Note that the social network effects (term $\Gamma \bar{f}$ ) cancel out in the comparison of groups $T 1$ and $T 0$ because they are common to both groups.

Individuals in group $T 0$ and individuals in group 0 do not receive the inducement letter but some of the peers of individuals in $T 0$ do receive the letter. As we have seen in Section 3 , because of network effects, individuals in $T 0$ are more likely to attend the fair than individuals in T0. As none of the individuals in groups $T 0$ and 0 receive the letter, there is no motivational reward effect involved in this comparison. More precisely, taking the average of equation (4) over groups $T 0$ and 0 , and taking the difference, we have

$$
\bar{y}_{T 0}-\bar{y}_{0}=E\left[y^{i} \mid T 0\right]-E\left[y^{i} \mid 0\right]=E\left[\gamma^{i}\left(f^{i}(T 0)-f^{i}(0)\right)\right]+\Gamma\left[\bar{f}_{T}-\bar{f}_{0}\right] .
$$

Hence, we finally obtain

$$
\frac{\bar{y}_{T 0}-\bar{y}_{0}}{\bar{f}_{T 0}-\bar{f}_{0}}=E\left[\gamma^{i} \mid f^{i}(T 0)-f^{i}(0)=1\right]+\Gamma \cdot \frac{\bar{f}_{T}-\bar{f}_{0}}{\bar{f}_{T 0}-\bar{f}_{0}} .
$$

Thus comparing group $T 0$ to group 0 provides an estimate of the sum of the direct average treatment effect for social interaction compliers and the social network effect.

Our analysis has shown that there are four parameters of interest in the model: the average treatment effect for financial reward compliers, the average treatment effect for social interaction compliers, the social network effect parameter $\Gamma$, and the motivational reward effect $\nu$. Our experiment provides us with only two instruments $L^{i}$ and $D^{i}$, thus it is clear that we cannot identify all four parameters together. Only if we make additional assumptions about two of these four parameters can we estimate the remaining two parameters. In the next subsection, we discuss three alternative assumptions under which the remaining parameters of the model could be estimated. We proceed not with the 
intention of claiming any particular set of assumptions is correct, but rather to explore the implications of each assumption.

\subsubsection{Interpretation under Alternative Identification Assumptions}

\section{- No motivational reward and no social network effects}

In that situation, both parameters $\Gamma$ and $\nu$ are equal to zero, and we can identify both average treatment effects for financial reward compliers and social interaction compliers. Under these assumption, equation (6) reduces to:

$$
\frac{\bar{y}_{T 1}-\bar{y}_{T 0}}{\bar{f}_{T 1}-\bar{f}_{T 0}}=E\left[\gamma^{i} \mid f^{i}(T 1)-f^{i}(T 0)=1\right] .
$$

Thus, the average treatment effect for financial reward compliers can be obtained by a simple IV regression of TDA enrollment on fair attendance on the sample of individuals in treated departments using $L^{i}$ as an instrument. Similarly, using (7), we have

$$
\frac{\bar{y}_{T 0}-\bar{y}_{0}}{\bar{f}_{T 0}-\bar{f}_{0}}=E\left[\gamma^{i} \mid f^{i}(T 0)-f^{i}(0)=1\right] .
$$

The average treatment effect for social interaction compliers can be obtained by an IV regression of TDA enrollment on fair attendance on the sample of individuals in $T 0$ or 0 groups using $D^{i}$ as an instrument. Column (2) and (3) in Table 4 present these IV estimates, for TDA enrollment 4.5 months and 11 months after the fair. Consistent with the reduced form evidence, the IV estimates suggest a positive treatment effect on social interaction compliers, and no effect on financial reward compliers. The results in column (3) can be thought of as an upper bound on the effects of the fair itself for the population of social interaction compliers. These individuals are not affected by the motivational reward, but if peers effects are present, the IV estimate in (9) would be an upper bound of the direct effect of the fair. This upper bound is 13.5 percentage points after 4.5 months, and 14.8 percentage points after 11 months. These effects are of comparable size (slightly higher) than those estimated by Madrian and Shea (2002) in a non-experimental 
set-up.

\section{- Constant Treatment Effects with no motivational reward effect}

If there is no motivational reward effect $(\nu=0)$ and the standard treatment effect $\gamma^{i}$ is the same across individuals and equal to $\gamma$, both parameters, $\gamma$ and $\Gamma$ of the structural equation (4) are identified and equation (6) reduces to

$$
\frac{\bar{y}_{T 1}-\bar{y}_{T 0}}{\bar{f}_{T 1}-\bar{f}_{T 0}}=\gamma
$$

This ratio is the IV estimate presented in column (2) in table 4, which we discuss above. Therefore, under these restrictive assumptions, we can conclude that the direct effect of the fair is zero for everyone. Taking the average of equation (4) over departments 0 and $T$, we obtain

$$
\bar{y}_{0}=(\gamma+\Gamma) \bar{f}_{0}+\bar{u}, \quad \bar{y}_{T}=(\gamma+\Gamma) \bar{f}_{T}+\bar{u} .
$$

Therefore the overall effect of fair attendance on TDA participation, taking into account all the social effects, is the ratio

$$
\frac{\bar{y}_{T}-\bar{y}_{0}}{\bar{f}_{T}-\bar{f}_{0}}=\gamma+\Gamma .
$$

This overall effect of one additional person attending the fair on TDA participation is the sum of the direct causal effect $\gamma$ of the fair, and the social effects $\Gamma$ from equation (4). These estimates (for participation after 4.5 months and after 11 months) are presented in column (1) in table 4 . In both cases, the overall effect of the fair is positive and significant. Under the assumptions made here, the difference of columns (1) and (2) gives an estimate of the social effect parameter. The implied estimates of $\Gamma$ are $10.14 \%$ and $6.7 \%$, after 4.5 and 11 months respectively. ${ }^{27}$

\footnotetext{
${ }^{27}$ Estimates of the direct and social effects parameters (and their standard errors) can also be directly obtained by an IV estimation of equation (4) (where $\gamma^{i}=\gamma$ ), using $D_{i}$ and $L_{i}$ as instruments.
} 


\section{- Constant Treatment Effects and no social network effects}

In this case, the standard treatment effect $\gamma_{S}$ (for those who did not receive the letter) can be obtained directly from (7), since $\Gamma=0$. In turn, equation (6), with the first term set to $\gamma_{S}$, can be used to recover $\nu$. Using the estimates of $\bar{f}_{T 1}$, and $\bar{f}_{T 0}$ from table 2 , we obtain an estimate of $\nu$ of 0.0927 after 4.5 months, and 0.0620 after 11 months. Under these assumptions, receiving the letter reduces the treatment effect of the fair by $69 \%$ for TDA participation after 4.5 months, and $42 \%$ for TDA participation after 11 months.

The distinction between differential treatment effects, social network effects, and motivational reward effects is clear conceptually but our experiment does not allow us to tell them apart. Thus, it is useful to describe what type of alternative experimental designs would be needed to separate these effects. Differential treatment effects arise in our setting because there is a first stage in our experiment where individuals decide whether or not to attend the fair. As a result, only a self-selected fraction of individuals attends the fair. Motivational reward effects arise because individuals receive a monetary payment for attending the fair.

Social network effects could be identified with the following experiment. Within a subsample of the "treated" departments, a subsample of employees would all attend automatically an information session. This could be done by making attendance a job requirement of employees. One could then test whether the TDA participation rises among the colleagues of the treated relative to that of individuals in untreated departments. Motivational reward effects could be estimated by paying people for attending an information session in a situation where everybody is supposed to attend. For example, in many firms, new hires are often invited to attend information sessions about benefits. In some departments, this information session could be presented as a normal process through which all new employees go. In other departments, attending this information session could be presented as voluntary but a financial reward could be offered for attendance (large enough to induce virtually everybody to attend). If everybody attends 
in both cases, the average treatment effect would be expected to be the same in both groups in the absence of a motivational reward effect. ${ }^{28}$ Evidence of differential treatment effects could potentially be obtained by using non-monetary incentives of various intensity to attend the fair. For example, some employees could be sent a letter simply reminding them of the benefits fair. Others could be sent a more pointed letter telling them that important information can be obtained at the fair. One could also use emails, personal phone calls or even remind them in person to attend the fair. These different encouragement designs are associated with different groups of compliers and may thus allow estimation of different fair treatment effects.

\subsection{Direct and Overall effects of the fair: comparisons with naive estimates}

The model developed clarifies the errors that can be done when ignoring social effects in experimental data. The data also allow us to compare experimental results with observational results. Table 6 presents alternative estimates of the effect of the fair.

Columns (1) and (2) are, respectively, the IV and the OLS estimates of the direct effect on TDA participation of attending the fair after 11 months; they are limited to employees in $T$ departments. ${ }^{29}$ The OLS estimate is 0.052 and significant. As we explained above, the direct effect of the fair can be estimated by running an IV regression of TDA participation on fair attendance in treated departments, using the dummy for receiving the letter as instrument. Given the lack of precision of the IV estimate, the two estimates are statistically indistinguishable, but the OLS estimate is more than three times as large as the IV estimate. This is not surprising, given that one would expect those who are more interested in benefits to be more likely to attend the fair. ${ }^{30}$

\footnotetext{
${ }^{28}$ Note that this setting would be close to the experiments carried out in the social psychology literature reviewed in Ross and Nisbett (1991).

${ }^{29}$ Since we do not know the identity of those who came to the fair except for those who received the invitation letter, the OLS estimate is obtained in the sample of those who received the letter.

${ }^{30}$ For example, as we noted earlier, the fraction of TDA participants is much higher among the sample
} 
Columns (3) and (4) present alternative IV estimates of the overall effect of the fair on TDA participation using the full sample (treated and control departments) of employees not enrolled in the TDA by September 2000. In column (3), we estimate the overall effect of the fair by an IV regression of TDA participation on average fair participation in each department, using the dummy for whether the department is treated as an instrument for average participation. The coefficients are 0.057 and 0.082 after 4.5 and 11 months and are significant. In column (4), we present the "naive", IV estimate that uses the letter dummy as an instrument, in the complete sample. This estimate lies between the estimate of the overall effect and the effect based on the $T 1$ versus $T 0$ comparison. The naive estimate would underestimate the overall effect of the fair (since part of the "control" group is actually treated) and overestimate the direct effect on those who received the letter. Ignoring the analysis we have developed in this paper would lead to a misguided causal interpretation of the effect of the fair on TDA enrollment.

\section{Interpretation and Additional evidence}

\subsection{Interpretation: Why did the experiment influence TDA par- ticipation?}

The striking results of the experiment are the large spillover effects at the fair attendance stage, and the fact that, despite the large remaining difference in fair attendance, there is no difference in TDA participation between the treated and untreated individuals within treated departments, while there is a significant difference in TDA participation between treated and untreated departments. As we discussed above, the first stage results are a clear indication of social effects in the decision to attend the fair, while the interpretation of fair attendees who did not receive the letter than among all employees (above 50\% versus around 30\%). This shows that TDA participants are more likely to attend the fair, probably because they are more interested in benefits information on average than non TDA participants (see Madrian and Shea (2002) for evidence of self-selection). 
of the TDA participation results is more delicate: they could be due to social effects, differential treatment effects, motivational reward effects, or a combination of the three. These three different explanations have, however, a common feature. They suggests that an individual's decision to participate in the TDA is affected by small changes in the environment, and not only by the information content of the fair.

If the results can be entirely explained by social effects, they suggest very strong peer effects, compared to the direct effect of the fair. This could be true in two models. In the first model, the fair conveys useful information, but any information obtained by a fair participant is completely diffused to the entire department he belongs to. This would explain why group $T 1$ individuals do not participate in the TDA any more than group T0 individuals $(\gamma=0)$, who in turn participate more than group 0 individuals $(\Gamma>0)$. This model has an additional testable implication: the effect of being in a treated department is entirely due to the increase in the probability that at least one member of the department attends the fair. Indeed, according to the registration data we collected at the fair, the probability that at least one department member attends the fair is much larger in treated departments (93\%) than in untreated departments (55\%). An implication of the model is thus that if, as one would expect, the difference in the probability that at least one member of the department attends the fair is larger in small departments than in large departments, the difference in TDA participation after 4.5 or 11 months between treated and control departments should also be larger within the smaller departments. Indeed, the difference between treated and untreated departments in the probability that at least one person attends the fair is $59 \%$ in the department of 81 employees or less (department size for the median employee), and $16 \%$ in the departments with more than 81 employees. However, as we show in panel A of table 5, the reduced form differences after 4.5 and 11 months are virtually identical in the two sets of departments. This rejects the hypothesis of complete diffusion of information.

Under the second model when individuals see more people attending the fair (or receiving a letter inviting others to attend the fair), they are directly induce to enroll in 
the TDA (irrespective of what those who went to the fair learnt at the fair or decided to do). Those peer effects thus do not seem to stem from a rational herd behavior in an environment where information is scarce or difficult to obtain (as in the models of Banerjee (1992) or Bikhchandani, Hirshleifer and Welch (1992)). At the same time, there is clearly no strong social pressure to conform to the decisions of the majority regarding the TDA (as is the case, for example, in the decision of adopt contraception for Bengladeshi women, as in Munshi (2000b)).

Another explanation for the results is that the treatment effects are different for different groups of compliers: it is positive for social interaction compliers, but zero for the financial reward compliers. In Table 5, we explore various observable characteristics which may lead to variations in the effect of the treatment. Column (1) reports average fair participation in each subgroup, among those who received the letter (we know the identity of those who attended the fair only for this group). Fair participation was larger in small departments than in large departments, and for women than for men. In column (2) and (3), we show the difference in TDA enrollment between treated and control departments after 4.5 and 11 months, respectively. After 4.5 months, the treatment effect seems somewhat larger in departments where the participation rate before the experiment was high (panel B) and average salaries are high (panel D). However, after 11 months, this difference shrunk (in panel B) or disappeared (in panel D). This suggests that it takes more time for those in departments with low initial participation and those with lower salaries to adjust their TDA participation. Panel $\mathrm{C}$ shows that the effects are the same for men and women. Overall, there is no evidence that treatment effects are widely different across groups defined by observables. Any differential treatment effect between financial reward and social interaction compliers is thus not attributable to observable characteristics. Of course, it could be due to an unobservable attribute uncorrelated with these observable characteristic (like interest in the benefits). Importantly, even if the results are entirely due to differential treatment effects, and social interactions take no part in explaining the second stage results, they are responsible for the variation in fair 
attendance among the untreated individual in treated departments. Thus, in this case as well, social network effects caused some people to take steps which ultimately led to change their TDA participation decision.

If the results are in part explained by the motivational reward effect, this would also provide evidence that individuals' decisions are influenced by small non-economic factors: when attending the fair on their own, they are influenced by it, but are not when they have been induced to go by the $\$ 20$ reward. A small perturbation in their motivation to attend the fair thus influences their final decision. Again, this suggests that individuals' process of decision making is influenced by small changes in the environments.

In summary, a common thread to all these potential explanations is that the participation decision is influenced by things other than new information about costs and benefits of the TDA. This, combined with the fact that the effect of the information fair itself was modest in absolute terms (the upper bound of the effect of the fair on the social interaction compliers, assuming no peer effects at the TDA participation stage is an increase of 14.8 percentage points in the participation rate after 11 months) suggests that an individual's decision to participate in the TDA is not taken as the outcome of a sophisticated decision process of information gathering and careful considerations of the alternatives. This is consistent with a growing body of evidence on retirement savings behavior, showing that individuals believe that their savings rate is too low (Choi et al. (2001a)), but that their project to increase it are rarely followed by action (Choi et al. (2001a), Madrian and Shea (2002)), and that retirement decision are characterized by very strong inertia and adherence to default rules (Madrian and Shea (2001), Choi et al. (2001b)). Thaler and Bertazi (2001) show that savings rates increase dramatically when individuals are offered to enroll in a program in which they commit now to save a portion of their future increase in earnings. We now directly examine the relationship between information and decision-making in our experiment, by examining responses to a follow-up questionnaire we sent to a sample of employees. We find results consistent with the above-mentioned literature. 


\subsection{Follow up questionnaires}

A follow up questionnaire sent to 917 employees after the fair included two questions designed to measure the employees' knowledge of the retirement benefits system in the university, as well as questions to elicit alternative retirement savings options available to employees and to measure the extent of procrastination.

Analysis of survey data presents an additional challenge, as the response rate to our questionnaire was less than $50 \%{ }^{31}$ Clearly, people who respond form a selected group: for example, people who respond to the questionnaires are 8 percentage points more likely to enroll in the TDA after 6 months than those who received it but did not return the survey (the standard error is 0.017 ). As we have shown in section 4.2, the questionnaire itself had no causal effect on participation: thus this difference is entirely due to selection. Moreover, those who received the questionnaire and did not respond are less likely to enroll in the TDA after 6 months than those who did not get the questionnaire. ${ }^{32}$ In addition, the selection seems different in treated versus control departments. The response rate in treated departments is $45 \%$ (Table 1, panel D), while it is only $35 \%$ in control departments. It may thus not be very informative to compare the responses across samples. On the other hand, network effects within departments seem to have played an important role here too: the response rates among treated and untreated individuals within treated departments are essentially identical. A plausible explanation is that those who had received the fair invitation letter were able to tell their colleagues that we had delivered on our promise of sending the reward. Since the response rates are the same, the assumption that the selection process is the same is reasonable. Thus, we can compare the response among treated and untreated individuals within treated department. These responses are not representative of the population in general, but representative of the segment of the

\footnotetext{
${ }^{31}$ This is a common problem: the survey on savings intention by Choi et al. (2001a) had a response rate of $33 \%$

${ }^{32}$ Since we have shown above that the questionnaire had no causal effect on enrollment, this is a sign of selection.
} 
population that tends to respond to this type of questionnaires.

The results are presented in Table 7 . People who answered the questionnaire are more likely to have attended the fair than people who did not: in the treated group, $43 \%$ of the respondents to the questionnaire attended (while $28 \%$ of the entire treated population attended), and in the control group, $29 \%$ of the respondents attended (compared to $15.1 \%$ ). The difference in attendance $(14 \%)$ is similar to the difference in fair attendance between the two groups as a whole $(13.1 \%)$, which we had recorded at the fair. ${ }^{33}$ Respondents report very high satisfaction rates with the fair. Yet, the satisfaction is significantly higher for the control group than for the treatment group (95\% against 85\%). This difference is almost as large as the difference in fair attendance in this sample: it suggests either that the marginal fair participant induced by our reward was less likely to find the fair useful (thus supporting the hypothesis of differential treatment effects), or that having received the letter reduces fair satisfaction (supporting the motivational reward effect hypothesis).

In panel $\mathrm{B}$, we report the response to the question "why are you not enrolled in the TDA?", for those who report that they are not enrolled (none of them are actually enrolled). They could check as many answers as were applicable. Individuals in the treatment group are less likely to report that they lack information (20\% versus 30\%). The difference is significant at the $10 \%$ level. They are more likely to say that they want to enroll soon, but have not found the time yet (45\% versus $36 \%$ ), although the t-statistic is just 1.3. ${ }^{34}$ All the other reasons for not contributing are mentioned equally often in both groups. The reason "plan to enroll soon" is the single most often cited reason for not contributing in both groups. In panel $\mathrm{C}$, we match this answer with

\footnotetext{
${ }^{33}$ This similarity suggests that there was no systematic bias in the way we recorded departments at the fair-even though we recorded them for only $75 \%$ of the participants.

${ }^{34}$ The difference is $9 \%$, almost as large as the difference in fair participation: a simple IV on the probability to report that one want to enrol on whether an individual went to the fair, using the letter as instrument, would thus give a coefficient very close to 1, which is also what Madrian and Shea (2002) obtain: virtually all seminar attendee who were not yet enrolled in the plan were intending to enroll soon after the seminar.
} 
their future behavior. Actual behavior is correlated with intention (virtually nobody who did not declare that they intended to enroll did so) but falls well short of intention. Among untreated individuals, $16.7 \%$ of those who planned to enroll do so. Among treated individuals, $10 \%$ do so. ${ }^{35}$ Thus, letter individuals are more likely to have good intentions, but are also more likely to procrastinate.

Panel D shows the answer to the question "where do you obtain information about the TDA?" Not surprisingly, those in the treatment group are more likely to say that they obtain it from the fair (and the difference, $11 \%$, is close to the $14 \%$ difference in fair attendance). However, they are less likely to obtain information from the benefits fair information packet (77\% versus 93\%). Those two sources of information thus appear to be substitutes. The other sources of information seem to be used equally by both groups.

Panel E reports answers to the knowledge questions. The first question is whether the employee is or is not enrolled in the TDA (when we sent the letter, none of them were). Second, we asked them whether they know the number of vendors with whom their Defined Contribution (DC) benefits are invested. Employees are automatically enrolled in the DC plan and can choose to invest their contributions with four different vendors. Many employees have more than one vendor. If they do not make a choice, the benefits office randomly allocates them to one vendor.

Treatment and control groups are about as likely to know the number of vendors with whom they are contributing: $74 \%$ and $71 \%$, respectively, ventured to answer the question, and, in total $60 \%$ of each group gave the right answer. ${ }^{36}$ However, those who received the letter are significantly less likely to report knowing their TDA status (94\% versus 99\%), and less likely to give the correct answer (89\% versus 94\%). ${ }^{37}$ This could reflect

\footnotetext{
${ }^{35}$ This is in the ballpark of other studies. Following the survey conducted by Choi et al. (2001a), 14\% of those who intended to enroll in the TDA did. Following the financial education session in Madrian and Shea (2002), $14 \%$ of the attendees (who all intended to enroll) did.

${ }^{36}$ Those who did not answer are counted as having given the wrong answer.

${ }^{37}$ Incidentally, this level of misclassification underscores the importance of working with administrative data when studying TDA savings behavior.
} 
some over-confidence on their part, since this letter was sent only to those who were not contributing. This lends some support to the motivational reward hypothesis: in this group where the fair attendance was high, the treated group has less knowledge than the group that was not directly treated.

In summary, participation in the fair did not seem to have a large impact on the information set of those who received the letter: they seem to have substituted fair attendance for individual research. In fact, they are more likely to be unsure about their actual TDA status, and to wrongly report themselves as contributing even though they are not. However, they are less likely to think they they suffer from a lack of information, and more likely to plan to enroll soon. Of course, it does not imply that the fair did not have an impact on the information set of those who went to the fair without the letter (used here as the control group).

\section{Conclusion}

This paper has attempted to identify the causal effects of information and social interaction on employee decisions to enroll in an employer sponsored Tax Deferred Account retirement plan.

Our encouragement strategy successfully induced treated employees to attend a benefits fair. The experimental design allowed us to demonstrate that peer effects are an important factor in determining whether employees attend the fair. In the second stage of the study, we presented evidence that individuals affected by the experiment are indeed more likely to enroll in the TDA after the fair. Interestingly, we find that the direct causal effect of fair attendance on an attendee among those whom we directly induced to attend the fair by means of a financial reward seems to be very small compared to the effect of being in a department with high fair participation. We proposed three different interpretations, differential treatment effects, social network effects, and motivational reward effects, to account for these findings. Our experiment does not allow us to distinguish 
unambiguously among these interpretations, thus illustrating how the analysis of a simple experiment in a social and economic context may be substantially more complicated than expected.

We are, nevertheless, able to provide an upper bound to the effect of the benefits fair on enrollment: attending the fair increases TDA participation 11 months later by a maximum of $15 \%$ (in a sample of people who were initially not enrolled). Average TDA participation after 11 months is only $7.5 \%$ in the control group (of which $5 \%$ attended the fair). Mandatory fair participation might thus produce a non-negligible increase in the enrollment flow, comparable to the effect of introducing a $25 \%$ employer matching contribution (Choi et al. 2001a). However, it remains small compared to changing default enrollment rules (Madrian and Shea (2001)) or offering delayed enrollment, as in the enrollment the "Save More Tomorrow" program (Thaler and Bernatzi, 2001).

This paper also provides experimental evidence that social interactions are a powerful mechanism in the process of information acquisition (i.e., the decision to seek additional information). Individuals do not instantly learn about economic opportunities, and their informational environment has a strong effect on their economic decisions. Low household savings levels in the United States have concerned academics and policy makers. Recognizing that savings decisions are influenced by peers' savings decisions could improve our understanding of why individuals enroll in TDAs, and may provide a rationale for organizing 401(k)s through the workplace. The large effect of a small reward on fair attendance, amplified by social effects, also suggests that individuals do not optimally seek out and process information on their own. While the motivational reward effect must be addressed, encouraging employees to attend benefits fairs may be a useful complement to automatic enrollment.

Finally, this study has shown that it is relatively simple and inexpensive to carry out an experiment within a large firm to study important economic research questions. Moreover, organizational divisions within a firm provide an excellent structure in which to study the effects of social interaction in the workplace. We hope that our study will 
encourage this research process and induce more economists to tackle questions in labor economics using experiments. In particular, our analysis raised more questions than we were able to answer. Using results from this experiment as a first step, one could think of several alternative experimental designs that could precisely identify the effects we have described. 


\section{References}

Acemoglu, Daron and Joshua Angrist, 1999. "How Large are Human capital Externalities: Evidence from Compulsory Schooling Laws". Mimeo, MIT.

Angrist, Joshua, Guido Imbens, and Donald Rubin, 1996, "Identification of Causal Effects using Instrumental Variables.", Journal of the American Statistical Association, 91, 444-455.

Banerjee, A.V., 1992. A simple model of herd behavior. Quarterly Journal of Economics $107,797-817$.

Bayer, Patrick B., Bernheim, B.D., Scholz, K., 1996. "The Effects of Financial Education in the Workplace: Evidence from a Survey of Employers." NBER Working Paper No. 5655 .

Bernheim, B.D., Garrett, D.M., 1996. "The Determinants and Consequences of Financial Education in the Workplace: Evidence from a Survey of Households." NBER Working Paper No. 5667.

Bernheim, B. Douglas, Daniel M. Garrett and Dean M. Maki (1997). "Education and Saving: The Long-Term Effects of High School Financial Curriculum Mandates." NBER Working Paper No. 6085. Forthcoming Journal of Public Economics.

Bertrand, M., Mullainathan, S., Luttner, E., 2000."Network Effects and Welfare Cultures." Quarterly Journal of Economics, 115, 1019-1057.

Besley, T., Case, A., 1994. "Diffusion as a Learning Process: Evidence from HYV Cotton." Discussion Paper 174, RPDS, Princeton University.

Bikhchandani, S., Hirshleifer, D., Welch, I., 1992. "A theory of fads, fashion, custom, and cultural change as informational cascades" Journal of Political Economy, 100, 992-1026. 
Case, Ann and Lawrence Katz, 1991. "The Company you Keep: The Effect of Family and Neighborhood on Disadvantaged Youths." NBER Working Paper No. 3705.

Choi, J., Laibson, D., Madrian, B. and Metrick A., 2001a "For Better or for Worse: Default Effect and 401(k) Savings Behavior", NBER Working Paper No. 8651.

Choi, J., Laibson, D., Madrian, B. and Metrick A., 2001b "Defined Contributions Pensions: Plan Rules, Participants Decisions, and the Path of Least Resistance", NBER Working Paper No. 8655.

Cooper, J., M. P. Zanna, and P. A. Taves, 1978, "Arousal as a Necessary Condition for Attitude Change Following Induced Compliance." Journal of Personality and Social Psychology, 36, 1101-1106.

Duflo, Esther and Emmanuel Saez, 2000. "Participation and Investment Decisions in a Retirement Plan: The Influence of Colleagues' Choices." NBER Working Paper No. 7735, forthcoming Journal of Public Economics.

Engen, E.M., Gale, W.G., Scholz, J.K., 1996. "The Illusory Effect of Saving Incentives on Saving." Journal of Economic Perspective 10, 113-138.

Evans, W., Oates, W., Schwab, R., 1992. "Measuring Peer Group Effects: A Model of Teenage Behavior." Journal of Political Economy, 100, 966-991.

Festinger, L. and J. M. Carlsmith, 1959. "Cognitive Consequences of Forced Compliance." Journal of Abnormal and Social Psychology, 58, 203-210.

Foster, A.D., Rosenzweig, M.R., 1995. "Learning by Doing and Learning from Others: Human Capital and Technical Change in Agriculture." Journal of Political Economy 103, 1176-1209.

Imbens, Guido, and Joshua Angrist, 1994. "Identification and Estimation of Local Average Treatment Effects." Econometrica, 62, 467-476. 
Imbens, G., Irano, K., D. Rubin, A. Zhou, 2000. "Estimating the Effect of Flu Shots in a Randomized Encouragement Design", Biostatistics, 1(1), 69-88.

Katz, Lawrence F., Jeffrey R. Kling, Jeffrey B. Liebman, 2001. "Moving to Opportunity in Boston: Early Results of a Randomized Mobility Experiment.", Quarterly Journal of Economics, 116(2), 607-654.

Kremer, Michael and Edward Miguel, 2001 "Worms: Education and Health Externalities in Kenya." NBER Working Paper No. 8481.

Lepper, M. R., D. Greene, and R. E. Nisbett, 1973. "Undermining Children's Intrinsic Interest with Extrinsic Reward: A Test for the Overjustification Hypothesis." Journal of Psychology and and Social Psychology, 37, 688-714.

Madrian, Brigitte and Dennis F. Shea, 2001. "The Power of Suggestion: Inertia in 401(k) Participation and Savings Behavior." Quarterly Journal of Economics, 116(4), 11491187.

Madrian, Brigitte and Dennis F. Shea, 2002. "Preaching to the Converted and Converting those Taught: Financial Education in the Workplace." Mimeo Graduate School of Business, University of Chicago.

Manski, C., 1993. "Identification of Exogenous Social Effects: The Reflection Problem." Review of Economic Studies 60, 531-542.

Manski, C. 1995 Identification Problems in the Social Sciences. Harvard University Press, Cambridge.

Munshi, K., 2000a. "Social Learning in a Heterogenous Population: Technology Diffusion in the Indian Green Revolution." University of Pennsylvania Mimeo.

Munshi, K., 2000b. "Social Norms and Individual Decisions During a Period of Change: An Application to the Demographic Transition." University of Pennsylvania Mimeo. 
Permutt, Thomas, and J. Richard Hebel. 1989. "Simultaneous Equation Estimation in a Clinical Trial of the Effect of Smoking on Birth Weight." Biometrics 45, 619-22.

Poterba, J.M., Venti, S.F., Wise, D.A., 1996. "How Retirement Saving Programs Increase Saving." Journal of Economic Perspectives 10, 91-112.

Powers, Donald E., and Spencer S. Swinton, 1984. "Effects of Self-Study for Coachable Test Item Types," Journal of Educational Psychology 76, 266-278.

Ross, Lee and Richard E. Nisbett, 1991 The Person and the Situation: Perspectives of Social Psychology, Temple University Press: Philadelphia.

Sacerdote, Bruce, 2001, "Peer Effects with Random Assignment: Results for Dartmouth Roommates." Quarterly Journal of Economics, 116(2), 681-704.

Sorensen, Alan, 2001, "Social Learning in the Demand for Employer-Sponsored Health Insurance." UCSD Mimeo, 2001

Summers, Lawrence, 2000, "Helping America to Save More. Remarks by Treasury Secretary Lawrence H. Summers". Treasury News Press Release LS-524, April 4th.

Thaler, Richard H. and Shlomo Bernatzi, 2001, "Save More Tomorrow: Using Behavioral Economics to Increase Employee Saving." Mimeo Graduate School of Business, University of Chicago. 
Table 1: Descriptive Statistics, by groups

\begin{tabular}{|c|c|c|c|c|}
\hline & \multicolumn{3}{|c|}{ Treated departments } & \multirow{2}{*}{$\begin{array}{c}\text { Untreated } \\
\text { Departments } \\
\text { (group 0) } \\
\end{array}$} \\
\hline & $\begin{array}{c}\text { All } \\
\text { (group T) }\end{array}$ & $\begin{array}{c}\text { Treated } \\
\text { (group T1) }\end{array}$ & $\begin{array}{c}\text { Untreated } \\
\text { (group T0) }\end{array}$ & \\
\hline & $(1)$ & (2) & (3) & $(4)$ \\
\hline \multicolumn{5}{|c|}{ PANEL A: BACKGROUND CHARACTERISTICS } \\
\hline TDA participation & 0.010 & 0.009 & 0.011 & 0.012 \\
\hline before the fair (Sept. 2000) & $(.0015)$ & (.0021) & (.0022) & $(.0024)$ \\
\hline Number of observations & 4168 & 2039 & 2129 & 2043 \\
\hline \multirow[t]{2}{*}{ Sex (\% male $)$} & 0.398 & 0.400 & 0.396 & 0.418 \\
\hline & $(.0076)$ & (.0109) & (.0107) & $(.011)$ \\
\hline \multirow[t]{2}{*}{ Years of Service } & 5.898 & 5.864 & 5.930 & 6.008 \\
\hline & $(.114)$ & $(.161)$ & $(.16)$ & $(.157)$ \\
\hline \multirow[t]{2}{*}{ Salary } & 38547 & 38807 & 38297 & 38213 \\
\hline & (304) & (438) & (422) & (416) \\
\hline \multirow[t]{2}{*}{ Age } & 38.3 & 38.4 & 38.2 & 38.7 \\
\hline & $(.17)$ & $(.24)$ & $(.24)$ & $(.24)$ \\
\hline Number of observations & 4126 & 2020 & 2106 & 2018 \\
\hline \multicolumn{5}{|c|}{ PANEL B: FAIR ATTENDANCE (REGISTRATION DATA) } \\
\hline Fair attendance & 0.214 & 0.280 & 0.151 & 0.049 \\
\hline among non-TDA enrollees & $(.0064)$ & $(.01)$ & $(.0078)$ & $(.0048)$ \\
\hline Number of observations & 4126 & 2020 & 2106 & 2018 \\
\hline Fair attendance & 0.192 & & & 0.063 \\
\hline for all staff employ & $(.0132)$ & & & $(.0103)$ \\
\hline Number of observations & 6687 & & & 3311 \\
\hline \multicolumn{5}{|c|}{ PANEL C: TDA PARTICIPATION (ADMINISTRATIVE DATA) } \\
\hline TDA participation after & 0.049 & 0.045 & 0.053 & 0.040 \\
\hline 4.5 months & $(.0035)$ & $(.0049)$ & $(.0051)$ & $(.0045)$ \\
\hline Number of observations & 3726 & 1832 & 1894 & 1861 \\
\hline TDA participation after & 0.088 & 0.089 & 0.088 & 0.075 \\
\hline 11 months & $(.005)$ & $(.0071)$ & $(.007)$ & $(.0065)$ \\
\hline Number of observations & 3246 & 1608 & 1638 & 1633 \\
\hline \multicolumn{5}{|c|}{ PANEL D: RESPONSE RATE TO THE ADDITIONAL QUESTIONNAIRE } \\
\hline \multirow[t]{2}{*}{ Response rate } & 0.452 & 0.440 & 0.464 & 0.352 \\
\hline & $(.018)$ & $(.0201)$ & $(.0405)$ & $(.0402)$ \\
\hline Number of observations & 765 & 612 & 153 & 142 \\
\hline
\end{tabular}

Notes:

1-Standard errors in parentheses.

2-The first part of Panel B includes all individuals not enrolled in the TDA by

September 2000. The second part includes all employes (enrolled or not in the TDA)

3-The average fair participation in the non-treated department was obtained from the registration information collected at the fair. Since only $75 \%$ of the participants registered, the participation was adjusted by a proportionality factor.

4-Demographic information and TDA participation are all obtained from administrative data 
Table 2: Differences in background characteristics, fair attendance and TDA participation, by treatment status

\begin{tabular}{|c|c|c|c|c|}
\hline & $\begin{array}{c}\text { Treated depts. } \\
\text { vs untreated depts. }\end{array}$ & $\begin{array}{l}\text { Treated vs Untreated } \\
\text { in treated depts. }\end{array}$ & $\begin{array}{l}\text { Untreated in treated depts. } \\
\text { vs untreated depts. }\end{array}$ & $\begin{array}{c}\text { Treated } \\
\text { vs untreated depts. }\end{array}$ \\
\hline & $\mathrm{X}_{\mathrm{T}^{-}} \mathrm{X}_{0}$ & $\mathrm{X}_{\mathrm{T} 1}-\mathrm{X}_{\mathrm{T} 0}$ & $\mathrm{X}_{\mathrm{T} 0}-\mathrm{X}_{0}$ & $\mathrm{X}_{\mathrm{T1}}-\mathrm{X}_{0}$ \\
\hline & $(1)$ & $(2)$ & (3) & $(4)$ \\
\hline \multicolumn{5}{|c|}{ PANEL A- BACKGROUND CHARACTERISTICS } \\
\hline \multirow[t]{2}{*}{ Sex (\% male $)$} & -0.023 & 0.003 & -0.027 & -0.017 \\
\hline & $(.024)$ & $(.015)$ & $(.022)$ & $(.025)$ \\
\hline \multirow[t]{2}{*}{ Years of Service } & -0.169 & -0.061 & -0.089 & -0.205 \\
\hline & $(.386)$ & $(.252)$ & $(.384)$ & $(.362)$ \\
\hline \multirow[t]{2}{*}{ Salary } & 524 & 369 & 208 & 760 \\
\hline & (964) & $(561)$ & $(847)$ & $(1002)$ \\
\hline \multirow[t]{2}{*}{ Age } & -0.56 & 0.16 & -0.52 & -0.48 \\
\hline & $(.53)$ & $(.33)$ & $(.52)$ & $(.49)$ \\
\hline Number of observations & 6144 & 4126 & 4124 & 4038 \\
\hline \multicolumn{5}{|l|}{ PANEL B: FAIR ATTENDANCE } \\
\hline \multirow[t]{2}{*}{ Fair attendance } & 0.158 & 0.138 & 0.090 & 0.231 \\
\hline & $(.021)$ & $(.019)$ & $(.02)$ & $(.022)$ \\
\hline Number of observations & 6144 & 4126 & 4124 & 4038 \\
\hline \multicolumn{5}{|l|}{ PANEL C: TDA PARTICIPATION } \\
\hline TDA participation after & 0.0097 & -0.0068 & 0.0126 & 0.0075 \\
\hline 4.5 months & $(.0043)$ & $(.0063)$ & $(.0053)$ & $(.0048)$ \\
\hline Number of observations & 5587 & 3726 & 3755 & 3693 \\
\hline TDA participation after & 0.0141 & 0.0023 & 0.0133 & 0.0153 \\
\hline 11 months & $(.0063)$ & $(.0103)$ & $(.0082)$ & $(.007)$ \\
\hline Number of observations & 4879 & 3246 & 3271 & 3241 \\
\hline \multicolumn{5}{|c|}{ PANEL D: RESPONSE TO THE QUESTIONNAIRE } \\
\hline \multirow[t]{2}{*}{ response rate to the questionnaire } & 0.1516 & 0.0070 & 0.1655 & 0.1465 \\
\hline & $(.0366)$ & $(.0519)$ & $(.0521)$ & $(.0376)$ \\
\hline Number of observations & 907 & 765 & 295 & 754 \\
\hline
\end{tabular}

Notes:

1-Regression adjusted differences in means: departments were matched according to size and participation, and triplets of departments of similar contribution rate and size were formed.

The regressions control for the triplet to which the department belongs.

2-Standard errors (reported in parentheses below the coefficient) are corrected for clustering at the department level

3-The average attendance or participation in the non-treated department was obtained from the registration information collected at the fair. Since only $75 \%$ of the participants registered, the participation was adjusted by a proportionality factor.

4-Demographic information and TDA participation are all obtained from administrative data

5-The sample is restricted to individuals who were not enrolled in the TDA before the fair. 
Table 3: Individual and social effects on fair attendance

\begin{tabular}{lccc}
\hline \hline & \multicolumn{3}{c}{ Attended the fair } \\
\cline { 2 - 4 } & OLS & IV & IV \\
\cline { 2 - 4 } & $(1)$ & $(2)$ & $(3)$ \\
\hline Dummy for received letter & 0.138 & 0.132 & 0.133 \\
& $(.019)$ & $(.019)$ & $(.019)$ \\
Dummy for treated & 0.090 & & \\
department & $(.022)$ & & \\
& & & \\
Average number of & & 0.285 & \\
letters in the department & & $(.072)$ & \\
Average participation to the & & & \\
fair in the department & & & $(.094)$ \\
Observations & & & \\
\hline
\end{tabular}

Notes:

1- All regressions control for the triplet to which the department belongs

2-Standard errors (reported in parentheses) are adjusted for clustering at the department level 3-In the IV regressions, the instrument set consists of a dummy for whether the department is treated, a dummy for whether the individual received the letters, and the triplet to which the department belongs. 
Table 4: IV regressions: Effect of fair attendance on TDA participation

\begin{tabular}{|c|c|c|c|c|}
\hline & $\begin{array}{c}\text { T depts. } \\
\text { vs } 0 \text { depts. }\end{array}$ & $\begin{array}{c}\text { Letter vs non-letter } \\
\text { in } \mathrm{T} \text { depts. } \\
\end{array}$ & $\begin{array}{l}\text { Non-letter in T depts. } \\
\text { vs } 0 \text { depts. }\end{array}$ & $\begin{array}{l}\text { Letter indiv. } \\
\text { vs } 0 \text { depts. }\end{array}$ \\
\hline & $\left(\mathrm{y}_{\mathrm{T}}-\mathrm{y}_{0}\right) /\left(\mathrm{f}_{\mathrm{T}}-\mathrm{f}_{0}\right)$ & $\left(\mathrm{y}_{\mathrm{T} 1}-\mathrm{y}_{\mathrm{T} 0}\right) /\left(\mathrm{f}_{\mathrm{T} 1}-\mathrm{f}_{\mathrm{T} 0}\right)$ & $\left(\mathrm{y}_{\mathrm{T} 0}-\mathrm{y}_{0}\right) /\left(\mathrm{f}_{\mathrm{T} 0}-\mathrm{f}_{0}\right)$ & $\left(\mathrm{y}_{\mathrm{T} 1}-\mathrm{y}_{0}\right) /\left(\mathrm{f}_{\mathrm{T} 1}-\mathrm{f}_{0}\right)$ \\
\hline & $(1)$ & $(2)$ & (3) & $(4)$ \\
\hline TDA participation after & 0.0568 & -0.0446 & 0.1348 & 0.0300 \\
\hline 4.5 months & $(.0257)$ & $(.0402)$ & $(.0625)$ & $(.0195)$ \\
\hline Number of observations & 5587 & 3726 & 3755 & 3693 \\
\hline TDA participation after & 0.0817 & 0.0142 & 0.1488 & 0.0599 \\
\hline 11 months & $(.0399)$ & $(.0641)$ & $(.102)$ & $(.029)$ \\
\hline Number of observations & 4879 & 3246 & 3271 & 3241 \\
\hline Sample & $\mathrm{T} 1, \mathrm{~T} 0,0$ & $\mathrm{~T} 1, \mathrm{~T} 0$ & T0,0 & $\mathrm{T} 1,0$ \\
\hline Instruments & Treated department & Received letter & Treated department & Received letter \\
\hline
\end{tabular}

Notes:

1- Dependent variables are individual enrollment in the TDA 4.5 months and 11 months after the fair

2- Independent variable is individual fair attendance

3- All regressions control for the triplet of the department

4- Standard errors (in parentheses) are corrected for clustering at the department level 
Table 5: Fair attendance and treatment effect in different groups

\begin{tabular}{|c|c|c|c|}
\hline & \multirow[b]{2}{*}{$\begin{array}{l}\text { Fair attendance in } \mathrm{T} 1 \\
\text { (letter recipients) }\end{array}$} & \multicolumn{2}{|c|}{ Difference Group T-Group 0} \\
\hline & & $\begin{array}{l}\text { TDA participation } \\
\text { after } 4.5 \text { months }\end{array}$ & $\begin{array}{l}\text { TDA participation } \\
\text { after } 11 \text { months }\end{array}$ \\
\hline & $(1)$ & (2) & (3) \\
\hline \multicolumn{4}{|c|}{ PANEL A: DEPARMENT SIZE } \\
\hline \multirow[t]{2}{*}{ Below median $(81)$} & $\begin{array}{r}0.328 \\
(.015) \\
005\end{array}$ & $\begin{array}{r}0.009 \\
(.0071)\end{array}$ & $\begin{array}{r}0.013 \\
(.0106) \\
0\end{array}$ \\
\hline & 985 & 2797 & 2403 \\
\hline \multirow[t]{2}{*}{ Above median ( 81$)$} & $\begin{array}{r}0.235 \\
(.0132)\end{array}$ & $\begin{array}{r}0.009 \\
(.0047)\end{array}$ & $\begin{array}{r}0.015 \\
(.0079)\end{array}$ \\
\hline & 1035 & 2790 & 2476 \\
\hline
\end{tabular}

PANEL B: DEPARTMENT AVERAGE PARTICIPATION IN THE TDA BEFORE THE EXPERIMENT

Below median (34\%)

(.0134)

1062

Above median (34\%)

0.304

(.0149)

958

PANEL C: GENDER

Women

0.320

(.0134)

1213

0.221

(.0146)

807

PANEL D: SALARY

Below Median (\$34021)

Above Median (\$34021)

\begin{tabular}{lrrr} 
Below Median (\$34021) & 0.269 & 0.001 & 0.015 \\
& $(.0141)$ & $(.006)$ & $(.0088)$ \\
& 983 & 2745 & 2291 \\
Above Median $(\$ 34021)$ & 0.291 & 0.018 & 0.015 \\
& $(.0141)$ & $(.0065)$ & $(.0104)$ \\
& 1037 & 2842 & 2588 \\
\hline
\end{tabular}

0.013

(.009)

2523

0.016

(.0094)

2356

.0064)

0.014

(.0112)

2843

$3298 \quad 2843$

$0.007 \quad 0.011$

$(.0071) \quad(.0086)$

22892036

1-The sample in column 1 is composed of individuals in group $\mathrm{T} 1$

2-Columns 2 and 3: Regression adjusted differences in means: department were matched according to size and participation, and triplets of departments of similar contribution rate and size were formed.

The regressions control for the triplet to which the department belongs.

3-Standard errors (reported in paretheses below the coefficient) corrected for clustering at the department level 
Table 6: Comparison with naive estimates: effect of the fair on TDA enrollment

\begin{tabular}{|c|c|c|c|c|}
\hline & \multicolumn{2}{|c|}{ Individual effect } & \multicolumn{2}{|c|}{ Overall effect } \\
\hline & IV & OLS & IV & "Naïve" IV \\
\hline & (1) & (2) & (3) & (4) \\
\hline \multicolumn{5}{|c|}{ A. Participation after 4.5 months } \\
\hline \multirow[t]{3}{*}{ Fair attendance } & -0.045 & 0.016 & 0.057 & 0.001 \\
\hline & $(.04)$ & $(.011)$ & $(.026)$ & $(.026)$ \\
\hline & 3726 & 1832 & 5587 & 5587 \\
\hline \multicolumn{5}{|c|}{ B. Participation after 11 months } \\
\hline \multirow[t]{3}{*}{ Fair attendance } & 0.014 & 0.052 & 0.082 & 0.042 \\
\hline & $(.064)$ & $(.018)$ & $(.04)$ & $(.039)$ \\
\hline & 3246 & 1608 & 4879 & 4879 \\
\hline Sample & $\begin{array}{c}\text { Treated } \\
\text { departments }\end{array}$ & $\begin{array}{l}\text { individuals who } \\
\text { received the letter }\end{array}$ & $\begin{array}{l}\text { Complete } \\
\text { sample }\end{array}$ & $\begin{array}{l}\text { Complete } \\
\text { sample }\end{array}$ \\
\hline Instrument & Received letter & NONE & Treated department & Received letter \\
\hline
\end{tabular}

Notes:

1- Dependent variables are individual enrollment in the TDA 4.5 months and 11 months after the fair

2- Independent variable is individual fair attendance

3- All regressions control for the triplet of the department

4- Standard errors (in parentheses) are corrected for clustering at the department level

5- The sample in column (1) is limited to individuals (not enrolled in the TDA by Sept. 2000) in Treated departments. The sample in column (2) is limited to individuals who received the letter (not enrolled in the TDA by Sept. 2000). The sample in column (3) and (4) is limited to individuals not enrolled in the TDA by Sept. 2000. 
Table 7: Effect of the fair on attitudes and knowledge

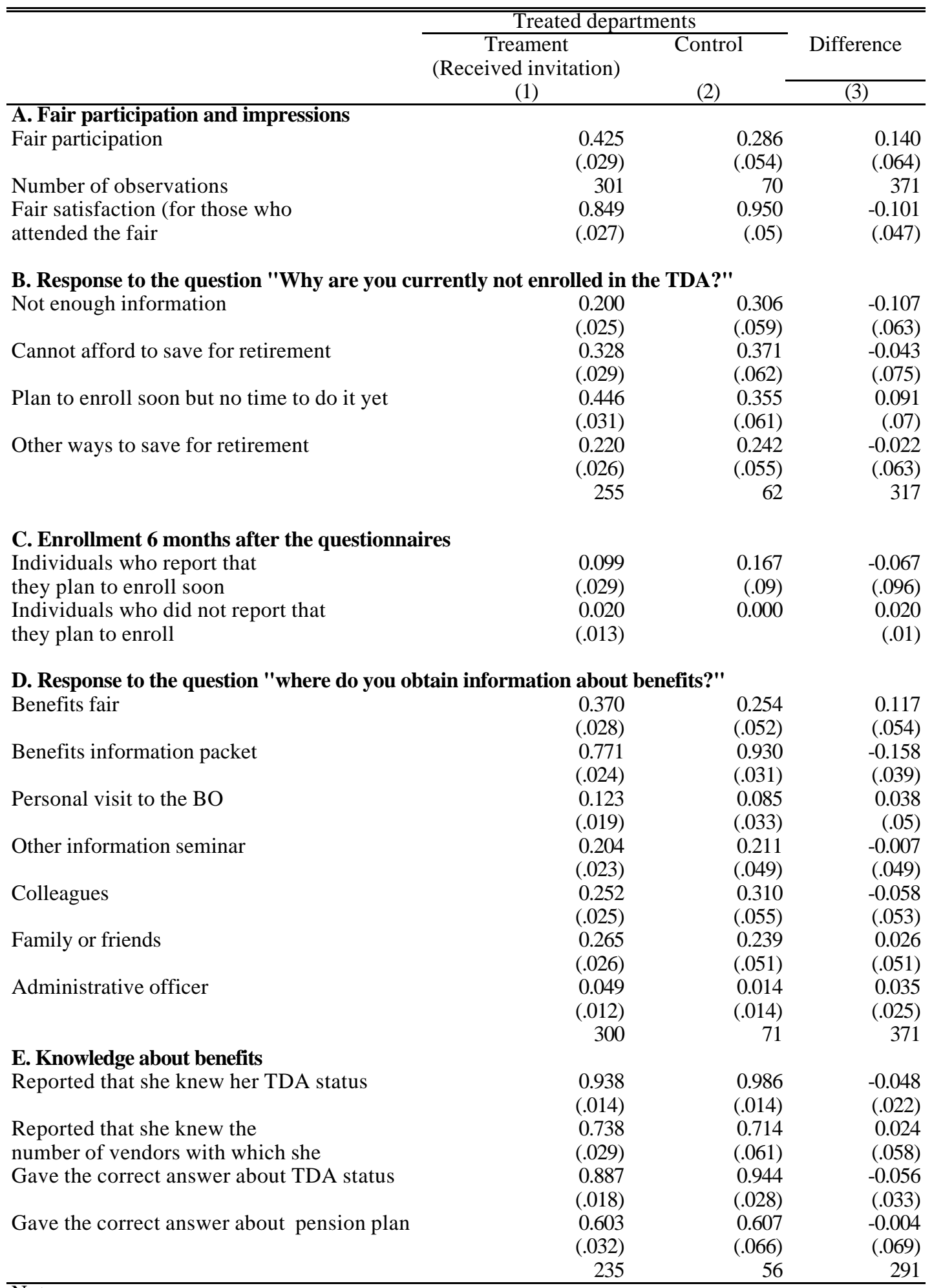

Notes

1-All statistics are weighted by population weight

2-Standard errors of the difference corrected for clustering at the department level

3-Sample is restricted to treated deparments 
October 31, 2000

Name

Line 1

Line 2

City state zip

Dear Name:

You have just received your Open Enrollment packet from the Benefits Services Group, inviting you to the Benefits Fair 2001.

The Fair will be held in two locations:

\author{
November 7, 11 am-2:30pm \\ ADDRESS ERASED
}

November 8, 11am - 2:30pm
ADDRESS ERASED

This year, as part of a study (conducted jointly by the Benefits Services Group and economics researchers) to better understand the impact of the Fair on benefits choices, we are offering a reward of \$20 to 2,000 employees, just for attending the Fair. Funding for these rewards was contributed from a research grant. We selected those employees by a simple lottery, and your name was among those drawn.

In order to receive this $\mathbf{\$ 2 0}$ reward, all you have to do is to come to the Fair with this letter, and give your name at the registration table that will be located in the main hall. You will receive a check within the two weeks following the Fair.

We hope that you will find the Fair helpful in making your benefits choices. However, we want to emphasize that the reward is completely independent of your benefits decisions.

Make a note of these dates (November 7 or November 8) in your calendar, and we look forward to seeing you there.

Sincerely yours,

Name of the Benefits Office

Associate Director 
April $1^{\text {st }}, 2001$

Name

Line 1

Line 2

City state zip

Dear Name:

We are currently studying whether benefits fairs, along with other way of obtaining information, convey the necessary information to members of the university community.

In the context of our study, we would like to ask you a few questions about your experience in obtaining information on the university retirement plans. If you could take a few minutes to complete the questionnaire attached to this letter, your response would be greatly appreciated. Your responses will be strictly confidential and will not be used for any purpose other than the study. You may mail your responses in the envelope provided.

As a token of our appreciation, we will send you a \$10 Macy's gift certificate when we receive the completed questionnaire. Please return the questionnaire on or before May 15.

Sincerely, 
First name, Last name

Please answer the following 6 simple questions. You can check the "don't know" answer if you are not sure of an answer. Your answers will remain strictly confidential and will be used for no purpose other than this study.

(1) In addition to your Basic Retirement Account, the university makes a monthly contribution of $3.5 \%$ of your monthly salary to an Individual Investment Account(s). You decide how this contribution should be invested from a list of four investment companies.

Through how many investment companies are you currently investing this contribution?

-One....
-Two....
-Three.....
-Four.....
-Don't know......

(2) The university offers a supplemental retirement plan called the Tax-Deferred Account (TDA) program. Through the TDA program, you can add to your retirement savings by contributing a portion of your salary on a pre-tax basis. You pay no taxes on these savings or the investment income until you withdraw your funds. You decide how much to contribute and the university deducts your contributions from your paycheck. You choose how to invest your savings from a wide range of funds offered by four different vendors You are not automatically enrolled in the TDA program.

Are you currently enrolled in the Tax-Deferred Account (TDA)?

-Yes ..... (go to question 4)

-No .....

-Don't know........

(3) [To be filled out only if you are not currently enrolled in the TDA] Why are you currently not enrolled in the TDA (check all answers that apply)?

-You do not have enough information on the TDA:

-Right now, you cannot afford to save for your retirement:

- You plan to enroll soon, but did not have the occasion to do it yet: ......

-You save for your retirement through other means: ......

(NEXT PAGE, PLEASE) 
First name, last name.

(3b) If you check the last answer, which other means are you using to save for retirement:

-TDA through spouse's employer:

-Individual Retirement Account (IRA): ......

-Employer provided pension plan (own):

-Employer provided pension plan (spouse): ......

-Other mutual funds:

-Other......

(4) [To be filled out by everybody]

From which of the following sources do you get information about the retirement plans (check all that apply)?

-The benefits information fair: .......

-Benefits information packet:

- You came in person to the Benefits office: .......

-You attended an information seminar:

-Colleagues:.......

-Family or friends:.........

- The Administrative Officer of your department: ........

-None......

(5) Did you attend the benefits information fair in the fall?

-Yes: .....

-No: ......

(6) If you did, did you find it useful?

-Yes:.........

-No: ........ 